\title{
Advanced Greenhouse Horticulture: New Technologies and Cultivation Practices
}

\author{
Athanasios Koukounaras
}

check for

Citation: Koukounaras, A. Advanced Greenhouse Horticulture: New Technologies and Cultivation Practices. Horticulturae 2021, 7, 1. https://dx. doi.org/10.3390/horticulturae7010001

Received: 19 December 2020 Accepted: 22 December 2020 Published: 24 December 2020

Publisher's Note: MDPI stays neutral with regard to jurisdictional claims in published maps and institutional affiliations.

Copyright: (c) 2020 by the author. Licensee MDPI, Basel, Switzerland. This article is an open access article distributed under the terms and conditions of the Creative Commons Attribution (CC BY) license (https: / / creativecommons.org/ licenses/by/4.0/).
School of Agriculture, Aristotle University of Thessaloniki, 54124 Thessaloniki, Greece; thankou@agro.auth.gr

Abstract: Greenhouse horticulture is one of the most intensive agricultural systems, with the advantages of environmental parameter control (temperature, light, etc.), higher efficiency of resource utilization (water, fertilizers, etc.) and the use of advanced technologies (hydroponics, automation, etc.) for higher productivity, earliness, stability of production and better quality. On the other hand, climate change and the application of high inputs without suitable management could have negative impacts on the expansion of the greenhouse horticulture sector. This special issue gathers twelve papers: three reviews and nine of original research. There is one review that focuses on irrigation of greenhouse crops, while a second surveys the effects of biochar on container substrate properties and plant growth. A third review examines the impact of light quality on plant-microbe interactions, especially non-phototrophic organisms. The research papers report both the use of new technologies as well as advanced cultivation practices. In particular, new technologies are presented such as dye-sensitized solar cells for the glass cover of a greenhouse, automation for water and nitrogen deficit stress detection in soilless tomato crops based on spectral indices, light-emitting diode (LED) lighting and gibberellic acid supplementation on potted ornamentals, the integration of brewery wastewater treatment through anaerobic digestion with substrate-based soilless agriculture, and application of diatomaceous earth as a silica supplement on potted ornamentals. Research studies about cultivation practices are presented comparing different systems (organic-conventional, aeroponic-nutrient film technique (NFT)-substrate culture), quantitative criteria for determining the quality of grafted seedlings, and of wild species as alternative crops for cultivation.

Keywords: soilless culture; light; protected cultivation; vegetables; ornamental

\section{Introduction}

Horticulture is characterized by a wide range of cultivation systems (i.e., open field, soilless, protected, greenhouse, organic, indoor) and a plethora of fruit, vegetable and ornamental species. Among these, greenhouse horticulture is one of the most intensive agricultural systems, focusing on the production of high-value products. Control of environmental parameters (temperature, light, etc.), higher efficiency of resource utilization (water, fertilizers, etc.) and the use of high-tech systems (hydroponic, automation, etc.) provide opportunities for higher yields, earliness, stability of production and better quality. The value of the global greenhouse horticulture market for 2019 was 30 billion US dollars and it has been projected to increase annually around $9 \%$ for the next five years [1]. Increasing demand for greenhouse horticultural crops could be explained by the growth of the world population as well as adaptation to negative environmental impacts of future water availability and climate change scenarios.

Climate change especially could have a significant effect on greenhouse horticulture since the environmental parameters inside greenhouses are dependent on outside conditions such as temperature and solar radiation. On the other hand, the use of high inputs without suitable management could have negative environmental impacts. Thus, suitable cultivation practices and new technologies will be needed to achieve the maximum benefits from greenhouse horticultural production. 


\section{Special Issue Overview}

This Special Issue collects current research findings dealing with a wide range topics related to greenhouse horticulture. The papers can be broadly organized into two main subjects: (i) five original research articles about new technologies, and (ii) three reviews and four original research articles about cultivation practices.

\subsection{New Technologies on Advanced Greenhouse Horticulture}

Greenhouse horticulture has been one of the pioneering sectors of agriculture in the use of new technologies. This has increased due to increasing globalization as well as the requirement for more efficient use of resources and more sustainable farming practices. Castro et al. [2] review new technologies such as improved cover materials, light-emitting diode (LED) lighting, alternative nutrient resources, and sensors that are expected to contribute to more digital, automatic, and advanced greenhouse horticultural production.

In greenhouse horticulture, there is a significant need for energy cost reduction, since energy constitutes a substantial fraction of the total production costs. Motivated by the above, Ntinas et al. [3] evaluated and quantified a higher crop yield and improved quality of hydroponic tomato cultivated in a greenhouse, using the innovative technology of dyesensitized solar cells (DSSC) for the glass cover of the greenhouse. All energy harvested from the sun with the DSSC was used to cover part of the electrical consumption of the DSSC greenhouse as a renewable energy source, in comparison to a reference greenhouse that had a glass cover and a conventional electrical source that was provided by a grid (CONV greenhouse). The results from the DSSC greenhouse during the summer season were satisfactory, since shading had a positive effect on the qualitative characteristics of the tomato fruit of two commercial table tomato hybrids. Furthermore, surplus light, especially during summer when it is not needed for plant growth, was used for electrical generation by the photoselective DSSCs installed in the greenhouse roof covering. In future work, the DSSC greenhouse will be evaluated year round, focusing on wintertime.

Water and nitrogen deficit stresses are among the most critical growth limiting factors in crop production. Usually quite complex and problematic methods have been used to quantify the impact of water and nitrogen deficit stresses on plants. Elvanidi et al. [4] developed a model based on the classification tree (CT) method to analyze complex reflectance index datasets in order to provide visual assessments of plant water and nitrogen deficit stress. The results showed that the combination of MSAVI (Modified soil-adjusted vegetation index), mrNDVI (Modified red edge normalized difference vegetation index), and PRI (Photochemical reflectance index) had the potential to determine water and nitrogen deficit stress with $89.6 \%$ and $91.4 \%$ classification accuracy values for the training and testing samples. These results are promising for further design of a smart decision support system for better climate and irrigation management.

Light is one of the most important factors related to plant growth and development and therefore, using artificial lighting is common practice in commercial greenhouses with the use of light emitting diode (LED) technology rapidly replacing traditional lighting sources. Gibberellic acid $\left(\mathrm{GA}_{3}\right)$ is a hormone found in plants, which is produced in low amounts, and therefore synthetic $\mathrm{GA}_{3}$ is commonly used in commercial agriculture to manipulate growth and development. Mills-Ibibofori et al. [5] evaluated the above parameters and combinations on potted ornamentals. The results showed that light and $\mathrm{GA}_{3}$ have a synergistic relationship with each other regarding plant and floral development. More research needs to be conducted with diverse species using an array of LED lights with different spectra in combination with the plant hormone $\mathrm{GA}_{3}$ to control plant growth and flowering, as effects may be species dependent.

Urban agriculture is experiencing a resurgence in popularity in many parts of the world and can play a key role in recycling urban waste streams, promoting nutrient recycling, and increasing sustainability of food systems. Riera-Vila et al. [6] investigated the integration of brewery wastewater treatment through anaerobic digestion with substratebased soilless agriculture. The yield of three crops in the digested wastewater treatments 
was higher than with raw wastewater or a no fertilizer control, indicating that nutrients in the brewery wastewater can be recovered for food production and diverted from typical urban waste treatment facilities. The work showed how to solve some of the agronomic and technological challenges of this integration, but additional complementary research is needed pertaining to the economic, legal, and social challenges of this decentralized urban system.

In horticultural plants, silica ( $\mathrm{Si}$ ) is a nonessential element; however, its role as a needed supplement in soilless media is gaining interest. Therefore, Mills-Ibibofori et al. [7] conducted a study to determine the effects of diatomaceous earth (DE) as a Si supplement on three potted ornamentals under well-watered and water-stressed conditions. Several growth and flowering characteristics were improved, depending on the rate and application method, by application of DE. Benefits of DE included increased height, width, shoot dry weight, stem, and flower diameter. Future studies should further evaluate application of $\mathrm{DE}$ on a range of crops and stress conditions.

\subsection{Cultivation Practices on Advanced Greenhouse Horticulture}

Vox et al. [8] reviewed how greenhouse horticultural cultivation is a very intensive form of agriculture and could be environmentally unfriendly; therefore, application of novel, suitable cultivation techniques is essential to prevent problems developing from this type of production.

Probably the most sensitive daily work of the growers is irrigation management of the crops, balancing water availability with crop need. Decisions concerning irrigation schedules may be based on a grower's estimation of need on a daily basis for soil-based crops, while estimates for soilless systems require shorter time intervals. Nikolaou et al. [9] presented a comprehensive review of irrigation management in soil and soilless crop production in greenhouses, as well as the need for the development of a commercial irrigation controller unit in order to model and monitor the soil-plant-atmosphere utilizing artificial intelligence.

Recently, there has been an increasing demand for biochar application, carbon-rich material made from biomass, in horticulture crop production systems. Hunag and $\mathrm{Gu}$ [10] reviewed biochar production systems, biochar effects on container substrates characteristics, and biochar effects on plant growth when used in container substrates. Further studies will be needed for assessment of biochars as a result of promising results to date to fine-tune the pyrolysis process and incorporate formulae for diverse container substrates.

As mentioned previously, light is extremely important for the plants, however, covering materials alter available light for the plants in greenhouses, which may became a light intensity problem in greenhouses at circumpolar regions. Alsanius et al. [11] reviewed the impact of light quality on plant-microbe interactions, such as bacterial and fungal pathogens, biocontrol agents, and the phyllobiome. Relevant molecular mechanisms regulating light-quality-related processes in bacteria are described and knowledge gaps are discussed with reference to ecological theories.

Control of the protected environment of a greenhouse makes them suitable for organic production. Golubkina et al. [12] compared nine new leek cultivars under organic and conventional systems in a greenhouse. The results showed that organic cultivation resulted in higher dry matter, sugar, ascorbic acid and potassium content but lower nitrates in the pseudo-stems than conventional cultivation, but with the same cultivar ranking as for conventional management. Observation of the strong relationships between quality, antioxidant and mineral components in leek plants could provide wide possibilities in breeding programs for both conventional and organic management systems in greenhouses.

To maximize the benefits of the greenhouse environment, the choice of a soilless cultural system (SCS) is a common practice. Common forms of SCS are hydroponic but also aeroponic and aquaponics. Li et al. [13] compared an aeroponic to a hydroponic nutrient film technique (NFT) system for their effects on growth and root characteristics of lettuce. The results showed that aeroponic cultivation significantly improved root growth 
parameters (root biomass, root/shoot ratio, total root length, root area, and root volume). However, greater root growth in the aeroponic system did not lead to greater shoot growth compared with hydroponic culture due to the limited availability of nutrients and water. Further research is necessary to determine suitable pressure, droplet size, and misting intervals in the aeroponic system to improve the continuous availability of nutrients and water for lettuce cultivation.

The use of grafting is an environmentally friendly technology, safe for consumers and users, and may prevent biotic and abiotic disorders, and it is extensively used for watermelon. However, to enjoy the advantages of grafting, use of high quality grafted seedlings is a prerequisite. Based on the above, Bantis et al. [14] performed a study to set critical limits for objective measurements of grafted watermelon seedling quality categories as well as to suggest the most accurate and convenient among them for application by the end users (industry and growers). They concluded that crucial parameters were leaf and cotyledon area of scions, stem diameter, shoot and root dry weights as well as shoot DW/L, and Dickson's quality index as good indicators for categorizing grafted watermelon seedlings.

Recently, there has been an increased interest by consumers in alternative crop species with unique visual appearances and tastes as well as a source of bioactive compounds. Motivated by the above, Guarise et al. [15] evaluated two wild populations of hedge mustard as a potential leafy vegetable. A wide range of physiological parameters and chemical substances (leaf pigments, chlorophyll a fluorescence, sugars, ascorbic acid, total phenols, anthocyanins, nitrate) were determined. The results demonstrated that the two wild populations of Brassicaceae can be successfully grown in a greenhouse with nutritional value and quality characteristics similar to the most common commercial leafy vegetables. Further investigation will be required for evaluating postharvest quality and suitable storage conditions.

\section{Conclusions}

Greenhouse horticultural production is a very intensive method, and therefore the need for adopting new technologies and advanced cultivation practices are preconditions for successful production in a very competitive global environment. Moreover, the environmental impact of the above is more critical than ever to avoid negative impacts while achieving the goal of satisfactory food production for the increasing world population while improving agricultural sustainability.

Funding: This research received no external funding.

Acknowledgments: We gratefully acknowledge all the authors that participated in this Special Issues.

Conflicts of Interest: The authors declare no conflict of interest.

\section{References}

1. Available online: https://www.marketdataforecast.com/market-reports/greenhouse-horticulture-market (accessed on 14 December 2020).

2. Castro, A.J.; López-Rodríguez, M.D.; Giagnocavo, C.; Gimenez, M.; Céspedes, L.; La Calle, A.; Gallardo, M.; Pumares, P.; Cabello, J.; Rodríguez, E.; et al. Six Collective Challenges for Sustainability of Almería Greenhouse Horticulture. Int. J. Environ. Res. Public Health 2019, 16, 4097. [CrossRef] [PubMed]

3. Ntinas, G.K.; Kadoglidou, K.; Tsivelika, N.; Krommydas, K.; Kalivas, A.; Ralli, P.; Irakli, M. Performance and Hydroponic Tomato Crop Quality Characteristics in a Novel Greenhouse Using Dye-Sensitized Solar Cell Technology for Covering Material. Horticulturae 2019, 5, 42. [CrossRef]

4. Elvanidi, A.; Katsoulas, N.; Kittas, C. Automation for Water and Nitrogen Deficit Stress Detection in Soilless Tomato Crops Based on Spectral Indices. Horticulturae 2018, 4, 47. [CrossRef]

5. Mills-Ibibofori, T.; Dunn, B.L.; Maness, N.; Payton, M. Effect of LED Lighting and Gibberellic Acid Supplementation on Potted Ornamentals. Horticulturae 2019, 5, 51. [CrossRef]

6. Riera-Vila, I.; Anderson, N.O.; Hodge, C.F.; Rogers, M. Anaerobically-Digested Brewery Wastewater as a Nutrient Solution for Substrate-Based Food Production. Horticulturae 2019, 5, 43. [CrossRef]

7. Mills-Ibibofori, T.; Dunn, B.L.; Maness, N.; Payton, M. Use of Diatomaceous Earth as a Silica Supplement on Potted Ornamentals. Horticulturae 2019, 5, 21. [CrossRef] 
8. Vox, G.; Teitel, M.; Pardossi, A.; Minuto, A.; Tinivella, F.; Schettini, E. Sustainable Greenhouse Systems. In Sustainable Agriculture: Technology, Planning and Management; Salazar, A., Rios, I., Eds.; Nova Science Publishers Inc.: New York, NY, USA, 2010; pp. 1-79.

9. Nikolaou, G.; Neocleous, D.; Katsoulas, N.; Kittas, C. Irrigation of greenhouse crops. Horticulturae 2019, 5, 7. [CrossRef]

10. Huang, L.; Gu, M. Effects of Biochar on Container Substrate Properties and Growth of Plants-A Review. Horticulturae 2019, 5, 14. [CrossRef]

11. Alsanius, B.W.; Karlsson, M.; Rosberg, A.K.; Dorais, M.; Naznin, M.T.; Khalil, S.; Bergstrand, K.-J. Light and Microbial Lifestyle: The Impact of Light Quality on Plant-Microbe Interactions in Horticultural Production Systems-A Review. Horticulturae 2019, 5, 41. [CrossRef]

12. Golubkina, N.A.; Seredin, T.M.; Antoshkina, M.S.; Kosheleva, O.V.; Teliban, G.C.; Caruso, G. Yield, Quality, Antioxidants and Elemental Composition of New Leek Cultivars under Organic or Conventional Systems in a Greenhouse. Horticulturae 2019, 5, 39. [CrossRef]

13. Li, X.; Li, Q.; Tang, B.; Gu, M. Growth Responses and Root Characteristics of Lettuce Grown in Aeroponics, Hydroponics, and Substrate Culture. Horticulturae 2018, 4, 35. [CrossRef]

14. Bantis, F.; Koukounaras, A.; Siomos, A.; Menexes, G.; Dangitsis, C.; Kintzonidis, D. Assessing Quantitative Criteria for Characterization of Quality Categories for Grafted Watermelon Seedlings. Horticulturae 2019, 5, 16. [CrossRef]

15. Guarise, M.; Borgonovo, G.; Bassoli, A.; Ferrante, A. Evaluation of Two Wild Populations of Hedge Mustard (Sisymbrium officinale (L.) Scop.) as a Potential Leafy Vegetable. Horticulturae 2019, 5, 13. [CrossRef] 